\title{
Reducing barriers to accessing fistula repair: Implementation research in Ebonyi
}

\author{
Pooja Sripad \\ Population Council \\ Emmanuel Nwala \\ Population Council \\ Vandana Tripathi
}

Follow this and additional works at: https://knowledgecommons.popcouncil.org/departments_sbsr-rh

Part of the International Public Health Commons, Maternal and Child Health Commons, Obstetrics and Gynecology Commons, Social and Behavioral Sciences Commons, and the Women's Health Commons How does access to this work benefit you? Let us know!

\section{Recommended Citation}

Sripad, Pooja, Emmanuel Nwala, and Vandana Tripathi. 2018. "Reducing barriers to accessing fistula repair: Implementation research in Ebonyi," brief. Washington, DC: Population Council. 


\section{REDUCING BARRIERS TO ACCESSING FISTULA REPAIR: IMPLEMENTATION RESEARCH IN EBONYI}

\section{BACKGROUND}

Female genital fistula is preventable and surgically treatable, but women who lack access to quality healthcare often live with fistula for many years. For every 1,000 births, an estimated 2.11 women develop fistula in Nigeria $^{1}$ and despite the establishment of internationally accredited national fistula centers (NOFIC) across the country, the majority of women live with unrepaired fistula.

Formative research conducted in 2015 highlighted barriers that impact access to fistula care services, including lack of knowledge about fistula among lower level providers, women, and their families; transportation and financial costs; fear and stigma; weak community and facility referral systems; and lack of counseling services for women and communities.

\section{IMPLEMENTATION RESEARCH}

Population Council, in collaboration with EngenderHealth and the Fistula Care Plus (FC+) project, conducted implementation research to understand whether a comprehensive information, screening, and referral intervention reduces transportation, communication, and financial barriers to accessing preventive care, detection, and treatment of fistula in Ebonyi State. Following a baseline assessment, researchers implemented a multi-pronged intervention utilizing a mobile hotline, transport voucher, and mass media tools to increase community awareness. The 13-month intervention convened an initial training of 48 primary healthcare (PHC) providers and 46 community agents to better identify and refer women with fistula. Twenty-four PHC providers and 42 community agents received a refresher training following midline data collection, and an endline evaluation occurred after the intervention (Figure 1).

\section{Highlights}

- Implementation of a mobile hotline, community volunteers, job aids at primary health centers, and transport vouchers increased referrals and access to fistula repair services at specialized centers.

- More primary healthcare providers at endline recognize and refer fistula patients, though knowledge gaps and turnover remain.

- Fewer psychological, transportation, and financial barriers, and beliefs of supernatural causes of fistula were observed.

- The hotline and communityto-facility referrals improved access to fistula services for stigmatized populations.

- Health systems and external stakeholder support are essential for sustaining trends.

\section{FIGURE 1}

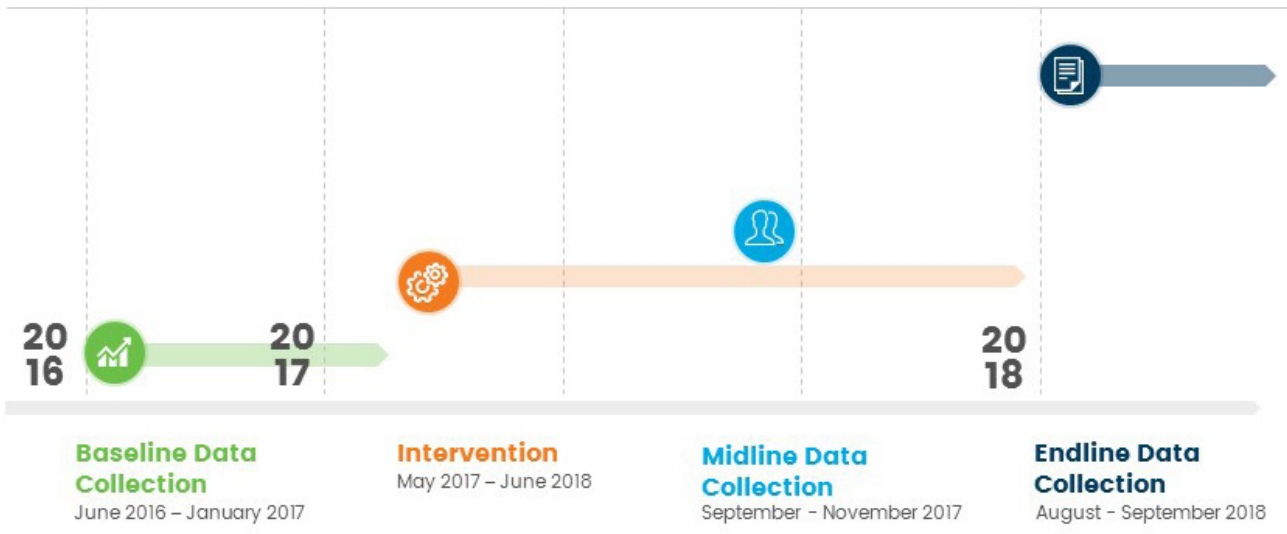

The Population Council conducts research and delivers solutions that improve lives around the world.

Big ideas supported by evidence: It's our model for global change. popcouncil.org (c) 2018 The Population Council, Inc. 


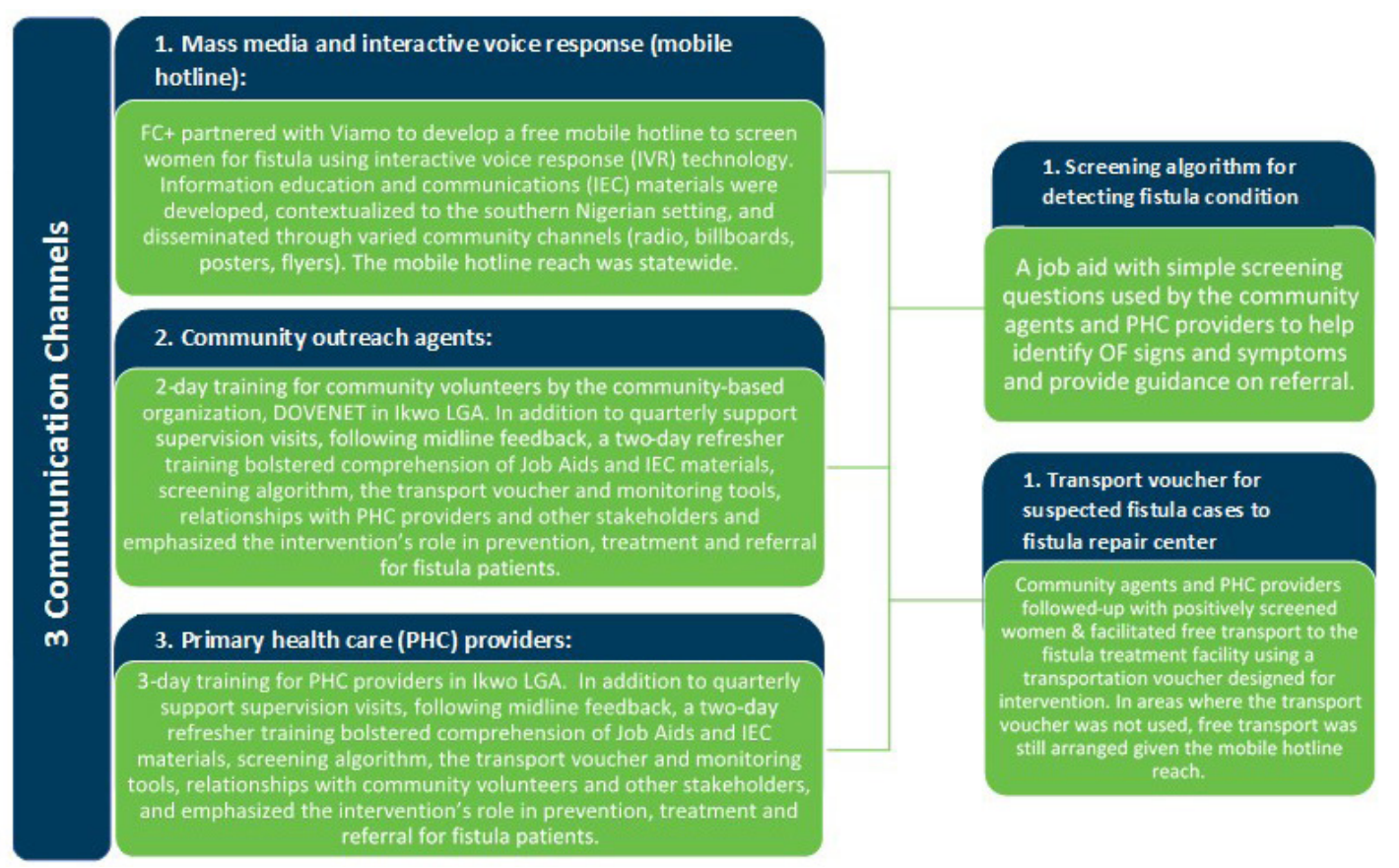

\section{Intervention}

The intervention, implemented by $\mathrm{FC}+$, followed a "31-1" model that applied three communication channels for messaging, one screening algorithm for detection at the PHC, and one transport voucher to enable access to a hospital for diagnosis and repair.

\section{Methods and Data Sources}

Mixed methods were used to investigate:

(a) Intervention outcomes, including fistula repair referrals, provider knowledge and practice, women's fistula status, barriers and enablers to care, and community awareness of fistula causes and care options (b) Challenges, successes, and sustainability implications for screening and referral at community and PHC levels using the hotline, job aides, and transport vouchers.

Data collection activities in Ikwo (intervention) and Izzi (comparison) local government areas (LGA) at baseline, midline and endline are outlined in Table 1.

While the mobile hotline component of the intervention was accessible throughout Ebonyi State, the intervention LGA refers to the additional community volunteer and PHC provider trainings and the transport voucher implementation conducted in Ikwo.

\section{TABLE 1: DATA COLLECTION ACTIVITIES}

\begin{tabular}{|c|c|c|c|c|}
\hline Method & Purpose & Baseline & Midline & Endline \\
\hline Assessment of PHC facility & Assessed health system capacity \& contextualized intervention setting & 39 & $\mathrm{n} / \mathrm{a}$ & 38 \\
\hline Assessment of Fistula Center & Tracked referrals and surgeries & 1 & $\mathrm{n} / \mathrm{a}$ & 1 \\
\hline Survey of PHC providers & $\begin{array}{l}\text { Assessed knowledge, attitudes, and operational challenges around } \\
\text { intervention implementation }\end{array}$ & 117 & $\mathrm{n} / \mathrm{a}$ & 100 \\
\hline Survey of post-repair women & Explored fistula history, experience of barriers and enablers & 91 & $\mathrm{n} / \mathrm{a}$ & 51 \\
\hline $\begin{array}{l}\text { In-depth interview with key } \\
\text { stakeholders: } \\
\text { - Community volunteers } \\
\text { - Community-based orgs. } \\
\text { - PHC providers } \\
\text { - Fistula center staff } \\
\text { - District health managers } \\
\text { - FC+ Uganda staff } \\
\text { - Post-repair clients }\end{array}$ & $\begin{array}{l}\text { Content validated barrier index among women living with fistula at } \\
\text { baseline; } \\
\text { and } \\
\text { Explored experiences of the implementation process from } \\
\text { implementers' and stakeholders' perspectives at midline and endline }\end{array}$ & 30 & 19 & 11 \\
\hline $\begin{array}{l}\text { Focus Group Discussion with } \\
\text { community men and women }\end{array}$ & $\begin{array}{l}\text { Explored barriers and enablers to accessing care and normative } \\
\text { attitudes toward fistula causes and consequences }\end{array}$ & 0 & $\mathrm{n} / \mathrm{a}$ & 8 \\
\hline $\begin{array}{l}\text { Program monitoring } \\
\text { statistics (from Viamo and } \\
\text { EngenderHealth) }\end{array}$ & $\begin{array}{l}\text { Assessed number of hotline callers, referrals, transport vouchers, } \\
\text { fistula center trips, and community-based follow up }\end{array}$ & & $\mathrm{n} / \mathrm{a}$ & $\mathrm{n} / \mathrm{a}$ \\
\hline
\end{tabular}




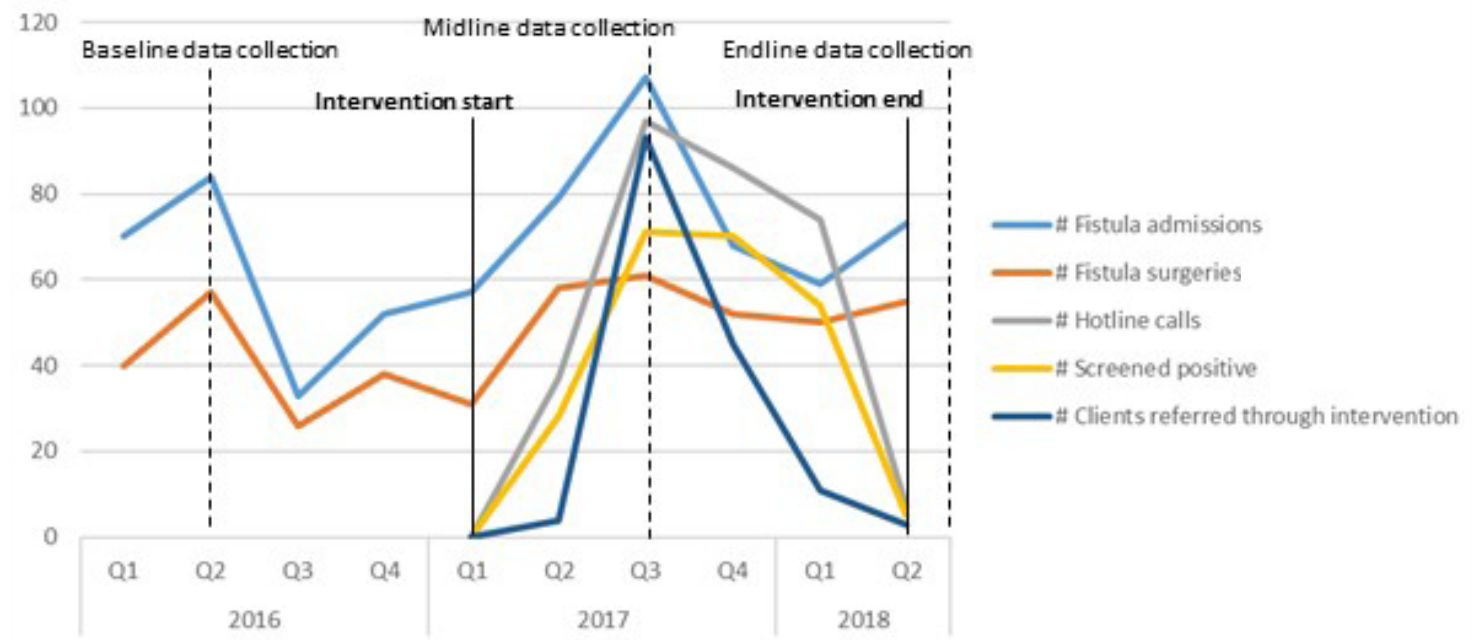

\section{FINDINGS}

\section{Facility Assessments}

PHC facility ownership remained constant from baseline to endline. With the exception of three faith-based facilities (7.9\%), all other PHC facilities are publicly owned (92.1\%). About half of providers are community health extension workers and the majority of facilities open daily, providing 24-hour services. Overall, the functionality of basic facility commodities, including electricity, generators, running water, toilets, and supplies remained constant from baseline to endline, though the number of power outages increased over time (66\% of facilities experienced outages at baseline, as opposed to $81 \%$ at endline).

The number of admissions and repair surgeries at fistlua centers, as documented in fistula center registers, increased during the intervention period (Figure 2). The hotline's reach beyond intervention communities suggests that the barrier reduction intervention may have played a role in improving access to fistula repair in Ebonyi. Program monitoring data show the increase, leveling and decrease in hotline callers, patients who were screened positive, and clients referred through any of the three communication channels, which follow the timeline and arc of intervention activities. Variation between numbers of admissions and surgeries completed could be due to factors unrelated to the intervention, such as challenges during pre-surgical preparation.

FIGURE 3: FISTULA RECOGNITION \& CARE PRACTICES OF PHC PROVIDERS (\%)

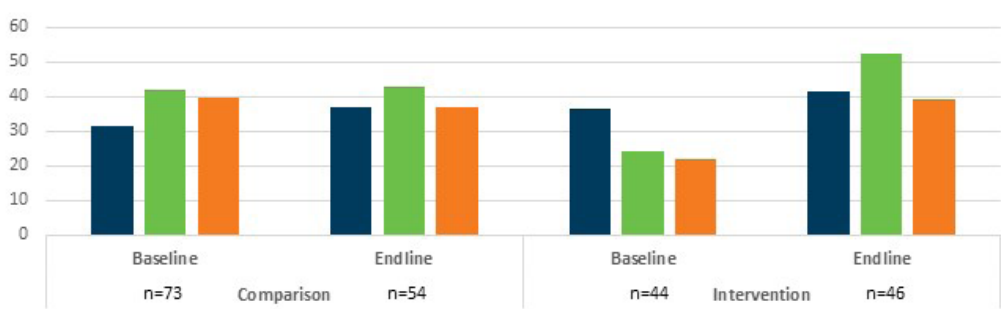

\section{PHC Providers}

Endline surveys took place with 54 and 46 providers in comparison and intervention communities, respectively. Findings were compared to baseline survey data from 73 and 44 comparison and intervention providers, respectively. PHC providers demonstrated moderate increases in recognition of fistula causes and symptoms following the intervention and subsequently made more referrals for fistula repair. More providers in intervention and comparison facilities recognized prolonged or obstructed laboratendline ( $41.3 \%$ and $37.0 \%$, respectively) than at baseline (36.4\% and $31.5 \%$, respectively), though these improvements were statistically non-significant (Figure 3).

Statistically significant improvements were seen among providers, who recognized leaking urine as a fistula symptom at intervention facilities at endline compared to baseline (52.2\% vs. $24.4 \%)$, and all providers across intervention and comparison facilities better recognized leaking urine as a fistula symptom at endline, compared to

\section{TABLE 2: FISTULA REPAIR CLIENT SURVEY}

\begin{tabular}{|c|c|c|}
\hline Fistula experience indicator & $\begin{array}{l}\text { Baseline } \\
n=91(\%)\end{array}$ & $\begin{array}{l}\text { Endline } \\
n=51(\%)\end{array}$ \\
\hline $\begin{array}{l}\text { Clients who began leaking post- } \\
\text { delivery (obstetric fistula) }\end{array}$ & $\begin{array}{l}76 \\
(84.6)\end{array}$ & $45(88.2)$ \\
\hline $\begin{array}{l}\text { Fistula cases following normal } \\
\text { delivery* }\end{array}$ & $29(38.2)$ & $\begin{array}{l}24 \\
(53.3)\end{array}$ \\
\hline $\begin{array}{l}\text { Years clients lived with fistula (any } \\
\text { sort) }\end{array}$ & $\begin{array}{l}\text { Mean: } \\
2.0 \text { yrs; } \\
\text { Range: } \\
1-4 \text { yrs }\end{array}$ & $\begin{array}{l}\text { Mean: } \\
2.7 \text { yrs; } \\
\text { Range: } \\
1-4 \text { yrs }\end{array}$ \\
\hline $\begin{array}{l}\text { Attempts to seek fistula treatment } \\
(\#)\end{array}$ & $\begin{array}{l}\text { Mean: } \\
1.6 ; \\
\text { Range: } \\
1-3\end{array}$ & $\begin{array}{l}\text { Mean: } \\
6.7 ; \\
\text { Range: } \\
1-19\end{array}$ \\
\hline $\begin{array}{l}\text { Women who have previously sought } \\
\text { fistula treatment }\end{array}$ & $\begin{array}{l}25 \\
(27.5)\end{array}$ & $\begin{array}{l}23 \\
(45.1)\end{array}$ \\
\hline
\end{tabular}




\begin{tabular}{|c|c|c|c|c|}
\hline \multirow[t]{2}{*}{ Barrier Index } & \multicolumn{2}{|c|}{ Baseline $(n=91)$} & \multicolumn{2}{|c|}{ Endline $(n=51)$} \\
\hline & $\mathrm{n}$ & $\%$ & $\mathrm{~N}$ & $\%$ \\
\hline I did not know that fistula is a medical condition that can be treated. & 38 & 42.7 & 27 & 52.9 \\
\hline I did not know where to go for fistula repair. & 16 & 18.6 & 9 & 17.6 \\
\hline I was told by health providers (in the past) that my fistula will heal itself. & 69 & 78.4 & 43 & 84.3 \\
\hline I was told by health providers (in the past) that my fistula cannot be treated. & 73 & 83.9 & 48 & 94.1 \\
\hline I did not have money to pay for medical care to treat my fistula. & 36 & 40.9 & 10 & 19.6 \\
\hline The cost of transportation to repair sites and accommodation was too high. & 31 & 35.6 & 12 & 23.5 \\
\hline I fear traveling to the health facility because of pain/discomfort during travel. & 40 & 46 & 23 & 45.1 \\
\hline $\begin{array}{l}\text { I did not have someone to support me in seeking/reaching care at the fistula } \\
\text { center*. }\end{array}$ & 73 & 83 & 27 & 52.9 \\
\hline I felt embarrassed because of my condition*. & 10 & 11.2 & 5 & 9.8 \\
\hline I felt isolated because of my OF condition*. & 28 & 32.6 & 12 & 23.5 \\
\hline I was afraid of harsh treatment by providers at the fistula center. & 69 & 78.4 & 41 & 80.4 \\
\hline \multicolumn{5}{|l|}{ Additional Barriers } \\
\hline I felt ashamed of having obstetric fistula. & 11 & 12.2 & 2 & 3.9 \\
\hline I felt worthless. & 31 & 34.8 & 6 & 11.8 \\
\hline I felt am not as complete as a person because of fistula. & 34 & 38.6 & 2 & 3.9 \\
\hline I believed that my fistula was caused by diabolic means. & 58 & 65.2 & 21 & 41.2 \\
\hline Once others learnt of my condition, they did not allow me to work/earn money. & 46 & 53.3 & 19 & 37.3 \\
\hline I felt embarrassed about smell/leaking while travelling to facility. & 16 & 18.4 & 3 & 5.9 \\
\hline
\end{tabular}

baseline (47.0\% vs. 35.9\%). Referral for women with fistula symptoms improved in the intervention facilities with more providers referring women at endline (39\%) than at baseline (22\%). While practices improved, providers' theoretical knowledge of urine and fecal leakage in the postnatal period remained low $(<5 \%)$ in intervention and comparison settings. This is likely due to focus on other maternal complications, such as bleeding and sepsis.

\section{Fistula Repair Clients}

Of the 91 women surveyed at baseline, $61.9 \%$ were between 15-35 years of age, $73.6 \%$ were married, $95.6 \%$ were Christian, and 3.3\% were Muslim. Eighty-eight percent had formal education ( $27.5 \%$ completed primary only) and nearly $60 \%$ ever worked for income. At endline, of 51 women surveyed, 53.3\% were between 15-35 years of age, $56.9 \%$ were married, $90.2 \%$ were Christian, and $5.9 \%$ were Muslim. Sixty-nine percent had formal education ( $60 \%$ completed primary only), and $72.5 \%$ had ever worked for income.

At baseline, more than $70.3 \%$ of women came to the fistula center from outside Ebonyi, whereas at endline, 47.1\% were from outside Ebonyi. The proportions of postdelivery fistula development increased from baseline to endline (see Table 2). On average, women at baseline and endline lived with fistula for 2-3 years, but at endline more women reported previous fistula treatment.

\section{Barriers to Care}

Endline survey results (Table 3 ) show significant reductions in women's feelings of embarrassment, isolation, and lack of family support in accessing fistula care $\left(p<0.05^{*}\right)$. Stigma and shame associated with uncontrollable leakage in public, two psychological barriers to care-seeking, decreased during the intervention (from $18.4 \%$ to $5.9 \%$ ). Fewer women avoided fistula repair due to inability to pay for medical care at endline ( $19.6 \%$ vs. $40 \%$ at baseline) and fewer believed fistula occurs because of supernatural causes ( $41.2 \%$ at endline vs. $65.2 \%$ at baseline).

More women at endline said they knew fistula was a medical condition that could be treated compared to baseline (53\% vs. 43\%). However, some awareness barriers remained, particularly at the provider level, as women continue to report being counseled by providers that their fistula will heal itself or cannot be treated. Awareness of where to go for fistula repair remained unchanged ( 18\% at endline and baseline).

\section{INTERVENTION PROCESSES, CHALLENGES, AND SUCCESSES}

Monitoring data from the $\mathrm{FC}+$ intervention show 301 women called the fistula hotline for information about fistula and repair care options. Two hundred twenty-eight women screened positive, and 200 received follow up from 
a community volunteer. Through the hotline, community volunteers, and PHC providers, 156 women were referred, and 177 trips to and from the fistula center occurred. Eighteen referrals came from the intervention LGA and were paid for using the transport voucher. Due in part to the hotline's reach, $90 \%$ of referred clients came from outside the intervention LGA. Stakeholders consider the intervention, especially the hotline and transport, integral to eliminating barriers to fistula care access. Offering multiple, non-stigmatizing information channels, and collaboration with transport agents promotes women's engagement in accessing repair care and prevents out-ofpocket spending.

\section{Training}

Intervention trainings were generally perceived as helpful in linking PHC providers and community volunteers and in building capacity to better prevent, identify, and refer for fistula. Providers in the intervention LGA demonstrated recall of training in birth preparedness, family planning, management of obstructed labor, and screening and referral through the job aid. PHC providers felt supported by a hands-on (refresher) training at the fistula center following midline feedback.

"The training was so organized, and we were taught how to use the job aid, transport voucher, and hotline."

-PHC Provider, endline

Community volunteers felt better able to sensitize communities and refer women for repair care through the intervention processes and their general community mobilization activities. Community volunteers requested additional trainings to sustain their work and mitigate community skepticism, which emerged as a concern.

"We are doing our work very well, we go house to house... when there is a gathering, we move together to sensitize the community so that they believe us."

-Community volunteer, endline

\section{Hotline}

Women, program managers, and others felt the hotline reduced stigma by providing confidentiality, particularly when the hotline was well-publicized and languagesensitive. The hotline's broad reach increased awareness, self- and community volunteer-guided referral, and transport to the fistula center.

"Because of stigma, the person thinks, 'it's just me and the radio gives the number' - [she] calls the number... it was a wonderful strategy and really helped." - Health program manager, endline

Implementers - managers and community volunteers described some hotline setbacks, including poor network connectivity and language challenges due to differences in local dialects. However, stakeholders found the hotline worthwhile, despite these concerns.

\section{Job Aids}

While some PHC providers reported not using the job aids, others found it useful in discussions with women about fistula. This corroborated women's experiences.

"It was during my health talk that a woman received information and later came back to me, so we did the hotline calls, arranged for transport, and she went for treatment at the fistula center."

-PHC provider, endline

"The message was very clear. The midwives explained that a free car will come and carry me from my house to where I will be cured through operation."

-Post-repair client, endline

Community volunteers had mixed feelings about the job aids and the hotline. In addition to language barriers, some reported women's lack of access or inability to use mobile phones. This led community volunteers to use their personal phones to call on the woman's behalf or to directly refer women with fistula symptoms to the PHC facility for screening.

"They [women] know that it [hotline] exists, but they don't know how to use it. They don't have phones; they don't hear lgbo; they don't hear English... [also for example] she doesn't know how to press the hotline."

-Community volunteer, endline

\section{Transport Voucher}

The transport vouchers were useful to NOFIC staff, drivers, and women themselves. Challenges to voucher use included confusion about the process of receiving and using it and communication gaps between implementers.

"I was given a transport voucher which enabled a private car to come and carry me from a PHC in Ikwo LGA to a fistula center. After the operation, the same car carried me home after I submitted the last voucher to the hospital."

-Post-repair client, endline

While in intervention areas the transport voucher enabled free transport to the fistula center, in comparison areas women either paid for their own transport, or if screened by the hotline, received reimbursement.

\section{Health Systems Environment}

Institutionalizing the job aids and trainings and sustaining linkages between stakeholders requires health systems support. Stakeholders perceived community volunteer engagement with the formal health system as integral in scaling up access to the NOFIC, especially given their proximity to, and familiarity with, communities where affected women live.

"More awareness should be raised so people know that

[fistula repair] is happening. If somebody had not told me, I wouldn't have known that they are curing it here."

-Post repair client, endline 
Stakeholders expressed concerns about the sustainability of each intervention component following FC+ exit interviews, asking whether women's access to PHC screening and repairs, enabled by community mobilization efforts, would continue. Concerns were raised about health worker turnover, limited PHC staff, and ambiguity about the NOFIC's ability to provide free repairs after financial support was withdrawn.

"Many in our locality call the hotline...the network may be bad, we may not get what you need at the exact moment, but the hotline will be okay."

-Community volunteer, endline

"I don't know if the NOFIC will treat them after this project ends."

-Community volunteer, endline

\section{CONCLUSIONS}

Reductions in psychosocial, financial, transportation, and some awareness barriers followed the implementation of the 3-1-1 intervention. Increases in admissions and surgeries at the intervention area fistula treatment center coincided with the intervention's implementation.

While myths around supernatural causes of fistula decreased, knowledge gaps on fistula care options persist among women and communities. These are likely linked to some prevailing awareness gaps at the PHC provider level. Mass media, mobile hotline, and community volunteer intervention channels improved referral and access to fistula centers, but in order to to be effective in a diverse state like Ebonyi, promotional and communications materials must be tailored to local dialects.

Improvements in the recognition of the causes of fistula among PHC providers implies that additional skills development trainings around counseling and referring patients with fistula symptoms could have similar impact. Though women continue to live with fistula for extended periods of time, the comprehensive and varied intervention approach, given adequate health systems support, emboldens women to seek repair services.

Study limitations reflect the challenge of measuring the effects of complex interventions in a real-world setting. The inability to isolate LGAs as purely intervention or comparison, due to the hotline coverage throughout Ebonyi State, limited researchers' ability to attribute observed changes to a component(s) of the intervention. A practical challenge was the lag between data collection and intervention timelines.

Researchers did not interview women living with fistula before they sought care or before they received repair, and given the rarity of the condition at the population level, faced challenges recruiting post-repair women at endline. Data were cross-sectional; longitudinal PHC provider surveys would have allowed increased claims to causality, but were not feasible for pragmatic reasons including turnover and selection for intervention trainings.

\section{KEY MESSAGES \& RECOMMENDATIONS}

- Complex interventions can be effective in reducing barriers to fistula treatment, but health systems and external stakeholders must ensure a supportive environment for sustainability.

- Coordination and communication between health systems and intervention actors to clarify roles and relationships can be achieved through refresher trainings.

- Trained PHC providers facilitated with adequate job aids can screen and refer fistula patients, thus improving access to treatment.

- Radio, hotline, and community agents were preferred sources of information for prevention and treatment information in communities.

- There is need for increased government support for referral and transport systems for fistula patients and their companions.

- With the expansion of interactive voice responsebased public health messaging, screening, and referral in low-resource settings, stakeholders should explore opportunities to integrate fistula - and other stigmatizing conditions - into existing platforms.

\section{CONTACT}

\section{Pooja Sripad}

Population Council, Washington D.C.

psripad@popcouncil.org

\section{Emmanuel Nwala}

Population Council, Abuja

enwala@popcouncil.org

Vandana Tripathi

EngenderHealth, Washington D.C. vtripathi@engenderhealth.org

\section{REFERENCE}

1 ljaiya MA, Rahman AG, Aboyeji AP, Olatinwo AW, Esuga SA, Ogah OK, Raji HO Adebara IO, Akintobi AO, Adeniran AS, Adewole AA. Vesico vaginal fistula: a review of Nigerian experience. West Afr J Med. 2010; 29(5):293- 8. 